\title{
A Comparative Study of Histopathological Analysis of Filum Terminale in Patients with Tethered Cord Syndrome and in Normal Human Fetuses
}

\author{
Ozkan Tehli $^{\mathrm{a}}$ Irgen Hodaj $^{\mathrm{a}}$ Cahit Kural $^{\mathrm{a}}$ Ilker Solmaz ${ }^{\mathrm{a}}$ Onder Onguru $^{\mathrm{b}}$ \\ Yusuf Izci ${ }^{a}$ \\ Departments of a Neurosurgery and ${ }^{b}$ Pathology, Gulhane Military Medical Academy, Etlik, Turkey
}

\section{Key Words}

Tethered cord syndrome $\cdot$ Filum terminale $\cdot$ Fetus

\begin{abstract}
Background: The structural changes in filum terminale (FT) may be responsible for tethered cord syndrome (TCS) in children. Although the histological changes in FT related to TCS are well-known, there is no comparative study of the changes which occur in TCS and normal fetal FT samples. The aims of this study are to compare the histological changes which occurred in FT samples of TCS and in fetuses, and to point out these changes. Methods: During the last 2 years, 14 cases of TCS were operated on, the FT was cut and the spinal cord was released. Among them, 6 samples of FT were obtained for histopathological examination. Moreover, 1 FT from an adult cadaver and 4 samples from fetal FT were obtained for the same examination. Results: While adipose tissue, fibrosis, hyalinization, and meningothelial proliferation were observed in FT samples of TCS, none of these findings were observed in fetal samples. Elastic fibers were present in all TCS specimens and the adult cadaver, but were not observed in fetuses. Peripheral nerves, ganglion cells and ependymal cells were observed in fetal FT samples. Conclusion: These changes probably begin at birth.
\end{abstract}

Copyright $\odot 2012$ S. Karger AG, Basel

\section{Introduction}

Filum terminale (FT) is a fibrous anatomical structure at the caudal ending of the spinal cord. It starts from conus medullaris at the L1-L2 level, and its intradural part ends at the S2 level $[1,2]$. Disorders that occurred in the period of secondary neurulation of embryonal life or events that cause stretching of the spinal cord affect also FT and disrupt its normal structure [3]. Deterioration of collagen fibers in the FT, irregularity, deterioration of vascular structures, increase in adipose tissue and hyalinization can be seen in patients with tethered cord syndrome (TCS) $[4,5]$. To date, many histological and ultrastructural studies on FT in patients with TCS have been performed, but there is no comparative study with normal fetal FT.

The aims of this study are to examine histologically the structure of FT in patients with TCS, to compare the results with the structure of fetal FT and to discuss the results in the literature.

\section{Materials and Methods}

The files of 14 patients with TCS operated within the last 2 years were retrospectively reviewed. Seven of them were adults and 7 were in the pediatric age group with a mean age of 14.4 years

\section{KARGER}

Fax +41 613061234 E-Mail karger@karger.ch www.karger.com

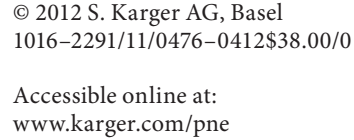



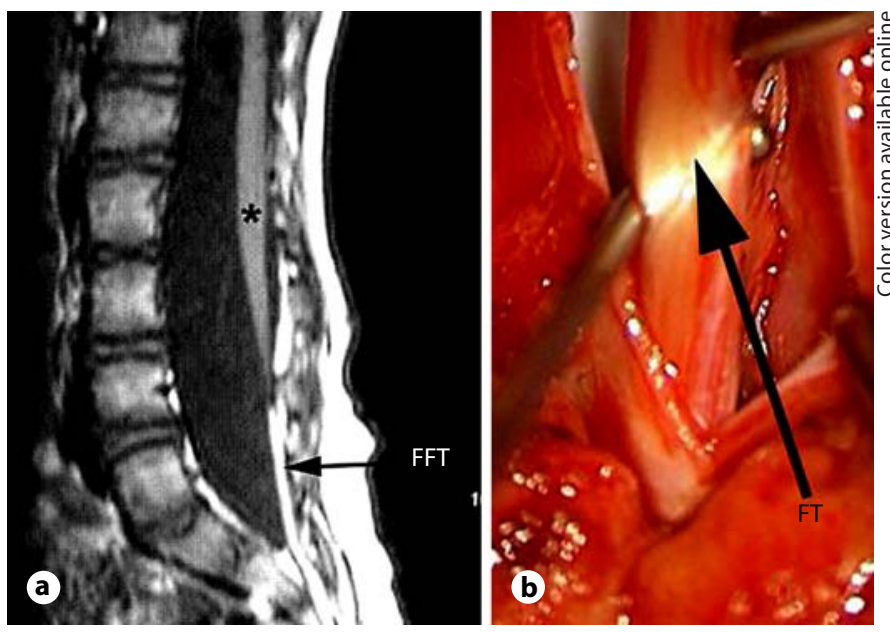

Fig. 1. a Sagittal $T_{1}$-weighted MRI section of case 2 (child) with TCS shows hyperintense fatty FT (FFT) ${ }^{*}=$ conus medullaris. b The intraoperative picture demonstrates yellow and thick FT.

(range 1-29 years). There were 13 males and 1 female. Fatty FT was observed radiologically and intraoperatively in 6 cases and they were included in this study. Four of them were children and 2 were adults. One of them was female and 5 were male. The mean age was 12 years (range 2-29 years). Among them, 4 had progressive walking disturbance and 2 had urinary disturbances. The FT was hyperintense in $\mathrm{T}_{1}$-weighted MRI of the patients. The level of the conus medullaris was at L4 in 3 patients and at L5 in 3 patients. FT samples were obtained for histological examination from these 6 cases (fig. 1).

Four fetal FT and 1 adult cadaveric FT samples were also obtained and included in this study (fig. 2). The ethical approval for this study was obtained from the National Ethics Committee (No. 7/18.1.2010). Three female and 1 male fetuses, between 24 and 28 weeks of gestational age and between 600 and 1,000 g of weight, were used in this study. There was no congenital malformation or disease of the central nervous system in the adult cadaver and fetuses. Samples of FT were stained with hematoxylin-eosin after formalin fixation. The Verhoeff stain was used for histochemical analysis of the elastic fibers. Neurofilament (monoclonal 1/100 Dako), epithelial membrane antigen (monoclonal, 1/200, Novacastra), glial fibrillary acidic protein (GFAP, monoclonal, 1/100, Novacastra) and S100 (monoclonal, 1/200, Invitrogen) stains were used for immunohistochemical analysis of the samples.

\section{Results}

The histological examination of the samples is presented in table 1 . The evaluation of the samples was based on 9 histological criteria: adipose tissue, fibrosis, calcification, meningothelial proliferation, peripheral nerve, ganglion cells, ependymal cells, elastic fibers and gliosis. Fibrosis and adipose tissue were observed in all cases with
Fig. 2. The isolation and section of fetal FT. CM = Conus medullaris; $\mathrm{CE}=$ cauda equina.

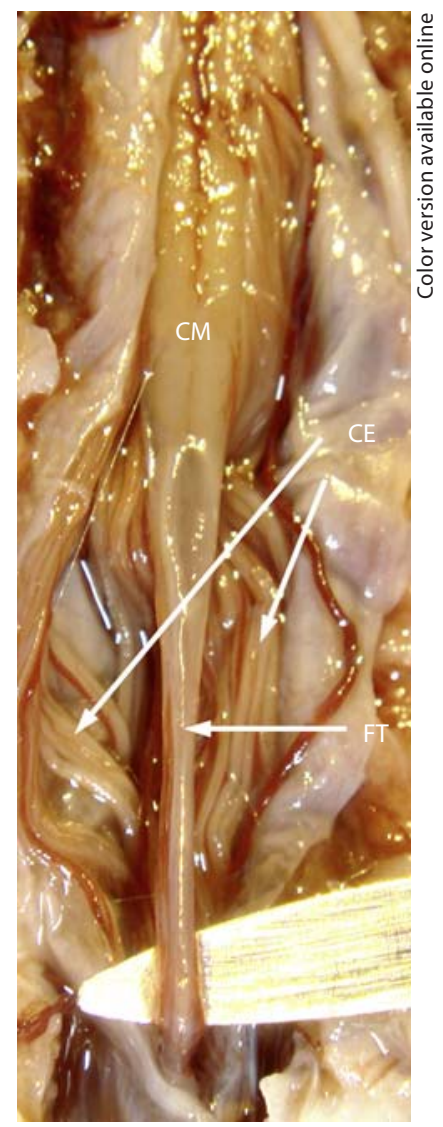

TCS. Meningothelial proliferation was observed in 4 patients. Concentric (psammomatous) calcification was observed only in 1 case. Peripheral nerve, elastic fibers, ganglion cells, gliosis and ependymal cells are the other structures which were observed in FT of TCS cases. The histopathological findings of case 2 were compared with a sample of fetal FT (fig. 3). Adipose tissue, fibrosis, calcification, elastic fibers and meningothelial proliferation were not observed in fetal FT samples. Ganglion cells, peripheral nerve, ependymal cells and gliosis were observed in fetal samples.

\section{Discussion}

The FT samples of 6 patients with TCS were examined histologically and the structure of FT was compared with 1 adult cadaver and 4 fetal FT samples. Varying degrees of adipose tissue, fibrosis and meningothelial proliferation were observed in FT samples of TCS, but none of them were observed in FT samples of the adult cadaver and the fetuses. In contrast, the peripheral nerve, gan- 
Table 1. Filum specimens: 6 patients with TCS, 1 adult cadaver and 4 fetuses

\begin{tabular}{|c|c|c|c|c|c|c|c|c|c|c|c|c|}
\hline No. & Age/sex & Diagnosis & $\begin{array}{l}\text { Level } \\
\text { of } \\
\text { conus }\end{array}$ & $\begin{array}{l}\text { Adipose } \\
\text { tissue }\end{array}$ & $\begin{array}{l}\text { Fi- } \\
\text { brosis }\end{array}$ & $\begin{array}{l}\text { Concentric } \\
\text { psammo- } \\
\text { matous } \\
\text { calcification }\end{array}$ & $\begin{array}{l}\text { Menin- } \\
\text { gothelial } \\
\text { prolifera- } \\
\text { tion }\end{array}$ & $\begin{array}{l}\text { Periph- } \\
\text { eral } \\
\text { nerves }\end{array}$ & $\begin{array}{l}\text { Gangli- } \\
\text { on cells }\end{array}$ & $\begin{array}{l}\text { Ependy- } \\
\text { mal cells }\end{array}$ & $\begin{array}{l}\text { Elastic } \\
\text { fibers }\end{array}$ & Gliosis \\
\hline 1 & 5 years $/ M$ & $\mathrm{SCM}+\mathrm{TCS}$ & $\mathrm{L} 4$ & ++ & ++ & - & + & + & + & + & ++ & + \\
\hline 2 & 2 years/M & Syr + TCS & L3 & ++ & +++ & + & + & - & - & - & + & - \\
\hline 3 & 7 years/M & TCS & $\mathrm{L} 4$ & + & +++ & - & + & - & - & - & + & - \\
\hline 4 & 29 years/M & dermal sinus + TCS & L3 & +++ & ++ & - & - & + & - & + & + & - \\
\hline 5 & 8 years $/ F$ & $\mathrm{SCM}+\mathrm{TCS}$ & L5 & + & ++ & - & - & +++ & +++ & + & + & + \\
\hline 6 & 21 years/M & dermal sinus + TCS & L3 & + & +++ & - & +++ & + & - & - & ++ & - \\
\hline 7 & adult cadaver & normal & - & - & - & - & - & +++ & - & - & + & +++ \\
\hline 8 & fetal filum (1) & normal & - & - & - & - & - & - & ++ & +++ & - & - \\
\hline 9 & fetal filum (2) & normal & - & - & - & - & - & +++ & +++ & ++ & - & +++ \\
\hline 10 & fetal filum (3) & normal & - & - & - & - & - & ++ & +++ & - & - & - \\
\hline 11 & fetal filum (4) & normal & - & - & - & - & - & - & - & ++ & - & ++ \\
\hline
\end{tabular}

$\mathrm{SCM}=$ Split cord malformation; Syr $=$ syringomelia.

glion cells, ependymal cells and gliosis were observed in intense proportions in fetal FT, but these structures were observed much less or not at all in cases with TCS. Concentric calcification was seen only in 1 patient.

Salbacak et al. [6], in their morphological study on 123 human fetuses, identified normal structure of the conus and FT in 78 fetuses, while they identified abnormal groove structure in the closure point of caudal neuropore or found a slight subsidence in 45 fetuses. In 30 fetuses, conus medullaris was abnormal in structure and shape. However, in 24 fetuses, FT was abnormal in structure (trough, subsidence, thickening and duplication). This study shows in more human fetuses than ever before that birth FT can be abnormal in structure. Although the number of samples is low, we did not observe any abnormal structure in 4 fetal FT. Our results did not support those of Salbacak et al., and we do not think that the abnormal fetal FT may play a role in the development of TCS.

Fontes et al. [7] performed an ultrastructural study in the longitudinal and transverse cross sections of the FT in 20 adult cadavers. They showed that the FT was composed of type 1 and 3 collagen bundles on a matrix of elastin and elaunin fibers. This structure provided the filum with a remarkable elasticity. They suggested that the changes in the type 1/type 3 collagen fiber ratio or in the amount of elastic fibers would have a role in the development of TCS. In our study, we did not find elastic fibers in any fetal FT samples. In contrast, we found elastic fibers in different proportions in all cases of child and adult patients with TCS. This suggests that elastic fibers may play a role in the development of TCS.

Choi et al. [8] showed that glial cells and neural components can be found in the normal structure of the FT. They also showed that residue of the central canal paved with ependymal cells can be found in FT. In our study ependymal cells were found in 3 of 4 samples of fetal FT. The ependymal cells were more intense than in cases with TCS. Ependymal cells were also observed in 3 cases with TCS. Peripheral nerves were additionally observed in TCS cases and samples of fetal FT.

Liu et al. [9] examined the structure of FT of 31 children with TCS by electron microscopy and suggested that it formed as a result of the loss of elasticity and deterioration of the structure of the FT of TCS. In this study, collagen bundles and adiposity had obtained an abnormal structure, while elastic and fibrillary fibers had become invisible or barely visible. Thickening, distortion, adhesion or fusion represented the most frequent anomalies in collagen fibers. These fibers were observed as blurred or crystallized in some regions. In our study, we did not perform staining for collagen fibers, but elastic fibers were absent in fetal FT samples. This finding showed that these fibers become visible after birth and probably play a role in the development of TCS during childhood or adulthood.

Yamada et al. $[10,11]$ divided TCS into 2 groups: group 1 included those with TCS secondary to any pathology, while group 2 included those with TCS with conus under the L2 level, 2-mm-thick FT and emerging in adulthood. 
Although the pathophysiology of group 1 is well-known, there are many speculations about group 2. Five of our cases were in group 1 and 1 case was in group 2 . Conus medullaris was below the $\mathrm{L} 2$ level in all cases. The thickness of FT was not measured in any case.

Gamble [12] performed the first ultrastructural study of conus medullaris and FT in human fetuses. In this study, the structures of conus and FT were examined by electron microscopy in 18 human fetuses and it was found that the structure of FT was created from collagen fibers and glial structures were also observed. This study also showed that conus medullaris and FT are derived from the distal end of the spinal cord as the result of some kind of degenerative process. In our study, no degenerative process in the structure of FT in fetuses was found. However, fibrosis was seen in histological sections of TCS and it was not observed in fetal and cadaveric FT. This finding showed that TCS is a partially degenerative process which occurs in FT.

Selçuki et al. [13] studied 21 samples of FT. Sixteen of them were obtained from patients with TCS and 5 were from normal cadavers. They showed loss of elasticity, deterioration of collagen structures and development of hyalinization in normal-appearance FT samples. In cases of TCS, even if FT is normal in morphological appearance,

Fig. 3. a-f Histopathological examination of FT belonging to case 2 (child) with fatty FT. a Fibrous stroma with massive collagen fibers and peripheral nerve tissue in the adipose tissue. HE. $\times 100$. b Area with elastic fibers. Verhoeff. $\times 400$. c Peripheral nerves staining with neurofilament. Immunohistochemistry. $\times 200$. d Epithelial membrane antigen-positive perineurial cells. Immunohistochemistry. $\times 200$. e GFAP positivity in the area of gliosis. Immunohistochemistry. $\times 200$. f Peripheral nerve tissue which was stained positive with S100 in the adipose tissue. Immunohistochemistry. $\times 200$. g-I Histopathological examination of a fetal FT. g Ganglion cells and peripheral nerves in the filum. HE. $\times 100$. $\mathbf{h}$ No elastic fibers were observed in the fetal FT. Verhoeff. $\times 100$. i Peripheral nerves staining with neurofilament. Immunohistochemistry. $\times 200$. j Epithelial membrane antigen positivity was not observed in the fetal filum sample. Immunohistochemistry. $\times 200$. $\mathbf{k}$ There is no gliosis area with GFAP-positive staining in the fetal filum. Immunohistochemistry. $\times 200$. I Ganglion cells and peripheral nerve tissue staining with S100. Immunohistochemistry. $\times 200$.
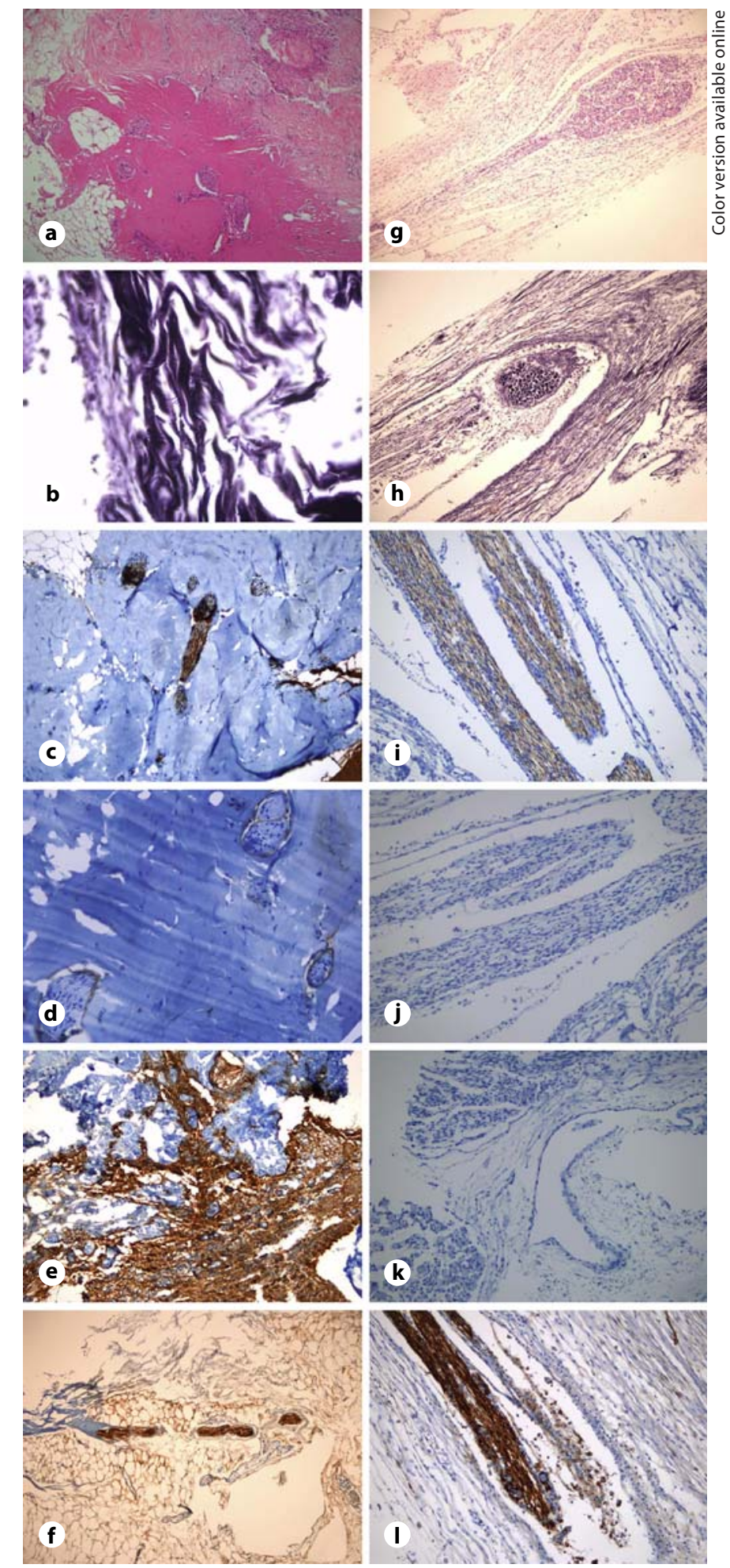

Filum Terminale in TCS and Normal

Pediatr Neurosurg 2011;47:412-416 
it is structurally deteriorated. In our series, all of the FT samples were yellow in color and appeared fatty. Fibrosis was observed in all FT samples, while meningothelial proliferation was observed in 4 cases. Concentric calcification was observed in 1 case. Unlike the study of Selçuki et al., we did not observe or cut any normal-looking FT. We studied only one cadaveric FT and saw that it had a normal structure. Fetal FT samples were rich in peripheral nerves, ganglion cells and ependymal cells; other features (adipose tissue, fibrosis, calcification and meningothelial proliferation) were not observed. Gliosis was intensely observed in 2 fetal FT and cadaveric FT, while it was very low only in 2 cases with TCS.

Selden et al. [14] investigated the occurrence of anatomical abnormalities of the terminal filum in children undergoing surgical filum lysis for minimal TCS and compared the results with three reference patients undergoing incidental terminal filum lysis during selective dorsal rhizotomy or resection of a lumbar dermal sinus tract. The samples consist of fragments of peripheral nerves, blood vessels, small amounts of fibrous connective tissue and occasional small amounts of ependyma in patients with a normal spinal cord. But the samples display dense fibrous tissue with minimal amounts of peripheral nerve or vessel in patients with a tethered cord.
Their results suggest that minimal TCS may be the result of structural abnormalities in the terminal filum rather than pathological sensitivity of the spinal cord parenchyma to normal amounts of traction. Our results also support that the structural changes in $\mathrm{FT}$ are responsible for the TCS in children.

The present study has 3 limitations. The first is the low number of samples for statistical analysis. In this study, it is difficult to mention the normal histological differences between adult and fetal FT specimens based on only 1 adult sample. The second is the lack of examination of collagen bundles in TCS and fetal samples. The relationship between the elastic fibers and collagen bundles is important in the development of TCS. The third is the difference in age between the patients with TCS and fetal controls. There is only 1 FT from an adult cadaver and this difference may affect the results of this study.

In conclusion, some histological changes occur in FT of cases with TCS. Because these changes are not observed in fetuses, it can be suggested that this syndrome did not begin in intrauterine life. However, more comparative studies are needed and more samples of fetal FT in larger TCS series need to be collected and examined.

\section{References}

- 1 Lee GY, Paradiso G, Tator CH, Gentili F, Massicotte EM, Fehlings MG: Surgical management of tethered cord syndrome in adults: indications, techniques, and long-term outcomes in 60 patients. J Neurosurg Spine 2006;4:123-131.

-2 Solmaz I, Izci Y, Albayrak B, Cetinalp E, Kural C, Sengul G, Gocmez C, Pusat S, Tuzun Y: Tethered cord syndrome in childhood: special emphasis on the surgical technique and review of the literature with our experience. Turk Neurosurg 2011;21:516521.

-3 Yamada S, Iacono RP, Androde T, Mandybur G, Yamada BS: Pathophysiology of tethered cord syndrome. Neurosurg Clin N Am 1995; 6:311-323.

4 Pinto FC, Fontes RB, Leonhardt Mde C, Amodio DT, Porro FF, Machado J: Anatomic study of the filum terminale and its correlations with the tethered cord syndrome. Neurosurgery 2002;51:725-729.
5 Yamada S, Won DJ, Yamada SM, Hadden A, Siddiqi J: Adult tethered cord syndrome: relative to spinal cord length and filum thickness. Neurol Res 2004;26:732-734.

6 Salbacak A, Büyükmumcu M, Malas MA, Karabulut AK, Seker M: An investigation of the conus medullaris and filum terminale variations in human fetuses. Surg Radiol Anat 2000;22:89-92.

-7 Fontes RB, Saad F, Soares MS, de Oliveira F, Pinto FC, Liberti EA: Ultrastructural study of the filum terminale and its elastic fibers. Neurosurgery 2006;58:978-984.

$\checkmark 8$ Choi BH, Kim RC, Suzuki M, Choe W: The ventriculus terminalis and filum terminale of the human spinal cord. Hum Pathol 1992; 23:916-920
$>9$ Liu FY, Li JF, Guan X, Luo XF, Wang ZL, Dang QH: SEM study on filum terminale with tethered cord syndrome. Childs Nerv Syst 2011;27:2141-2144.

10 Yamada S: Tethered cord syndrome in adults and children. Neurol Res 2004;26:717-718.

11 Yamada S, Zinke DE, Sanders D: Pathophysiology of 'tethered cord syndrome'. J Neurosurg 1981;54:494-503.

12 Gamble HJ: Electron microscope observations upon the conus medullaris and filum terminale of human fetuses. J Anat 1971;110: 173-179.

13 Selçuki M, Vatansever S, Inan S, Erdemli E, Bağdatoğlu C, Polat A: Is a filum terminale with a normal appearance really normal? Childs Nerv Syst 2003;19:3-10.

-14 Selden NR, Nixon RR, Skoog SR, Lashley DB: Minimal tethered cord syndrome associated with thickening of the terminal filum. J Neurosurg 2006;105(suppl 3):214-218. 